\title{
Nexavar in treatment of hepatocellular carcinoma
}

\author{
Gabriela SMIRA 1 , MD, Assoc. Prof. Adina CROITORU ${ }^{3}, \mathrm{MD}$, PhD, Andra VISAN ${ }^{3}, \mathrm{MD}$, Ioana LUCA ${ }^{3}$, \\ $M D$, Iulia GRAMATICU ${ }^{3}$, MD, Florina BUICA ${ }^{3}, M D$, loana DINU ${ }^{3}, M D$, \\ Assoc. Prof. Vladislav BRASOVEANU², MD, PhD, Doina HREHORET², MD, \\ Prof. Irinel POPESCU², MD, PhD \\ ${ }^{1}$ Center of Gastroenterology and Hepatology, Fundeni Clinical Institute, Bucharest \\ ${ }^{2}$ Center of General Surgery and Liver Transplantation, Fundeni Clinical Institute, Bucharest \\ ${ }^{3}$ Department of Oncology, Fundeni Clinical Institute, Bucharest
}

\begin{abstract}
Hepatocellular carcinoma (HCC) is a significant health problem. Globally is the second most common cause of cancer-associated death and the fifth most frequent neoplasm. The main risk factors for the onset of HCC are well recognized, including the presence of cirrhosis, chronic hepatitis $C$ and hepatitis $B$ infections and heavy alcohol consumption. In an early stage disease, there are potentially curative therapies, such as surgical resection, transplantation and loco-regional procedures. However, at the time of diagnosis, a large number of patients present an advanced stage disease, according to the Barcelona Clinic Liver Cancer (BCLC) classification.

Background. Sorafenib chemotherapy is the first-line therapy for patients with hepatocellular carcinoma (HCC) in an advanced stage. The aim of this study was to evaluate prognostic factors of survival in HCC patients treated with sorafenib, in real-life clinical practice.

Methods. We perform an retrospective, non-randomized study and we analyzed 162 patients with HCC who were treated with sorafenib $800 \mathrm{mg} /$ day in Oncology Department of Fundeni Clinical Institute between 2009 and 2016.

Results. Mortality in our patients group was more than $80 \%$, with survival rate about 22 months and a median survival rate 13 months. The patients with liver cirrhosis has a severe evolution compared with those who has hepatitis. We found a good survival rate for HCV infected patients compared with HVB or $V H B+V H D$ etiology. BCLC and Child-Pugh classification have an important role in overall survival.
\end{abstract}

Keywords: sorafenib, hepatocellular carcinoma, cirrhosis

\section{INTRODUCTION}

Hepatocellular carcinoma (HCC) constitutes the fifth most frequent form of cancer worldwide, and it holds the second place in malignancy related mortality (1). Hepatocellular carcinoma (HCC) accounts for $85 \%$ to $90 \%$ of all primary hepatic malignancies $(2,3)$. In the United States, the incidence of HCC has increased from 1.4 cases per 100,000 in 1976-1980 to approximately 5 cases per 100,000 in 2003-2006 (4-6). The main risk factors for the onset of HCC are well recognized, including the presence of cirrhosis, chronic hepatitis $\mathrm{C}$ and hepatitis $\mathrm{B}$ infections and heavy alcohol consumption (7). 
In an early stage disease, there are potentially curative therapies, such as surgical resection, transplantation and locoregional procedures. However, at the time of diagnosis, a large number of patients present an advanced stage disease, according to the Barcelona Clinic Liver Cancer (BCLC) classification (8).

Molecular-targeted therapeutic strategies offer new hope for effective palliative therapy in livedr cancer. Sorafenib (Nexavar) is an orally available multi-kinase inhibitor acting on several distinct tyrosine kinases. By inhibiting angiogenesis and cellular proliferation, sorafenib can block two of major signalling pathways of HCC expansion $(13,14)$. In a phase 3 SHARP trial involving 602 patients, sorafenib $400 \mathrm{mg}$ was moderately well-tolerated and associated with improved survival in $44 \%$ of patients resulting in 3 months extended survival in treated patients (10.7 months in the sorafenib arm versus 7.9 months in the control arm) (15). Sorafenib has established itself as the first option in patients with HCC who can no longer be treated with potentially more effective local therapies.

\section{MATERIALS AND METHODS}

We perform an retrospective, non-randomized study and we analyzed 162 patients who were diagnosed with HCC and treated in Oncology Department of Fundeni Clinical Institute between 2009 and 2016.

Sorafenib was given as first line therapy in advanced stage or as second line in intermediate stage patients after locoregional treatment, following assessment and indication from the multidisciplinary group special dedicated to this topic. Therapy regime was $400 \mathrm{mg}$ of sorafenib twice daily, except for those who reduced the dose to $400 \mathrm{mg}$ daily due to adverse events.

OS was measured from the starting date of sorafenib therapy until the date of the last contact.

\section{RESULTS}

In our study group, we calculated General Survival (Fig 1).

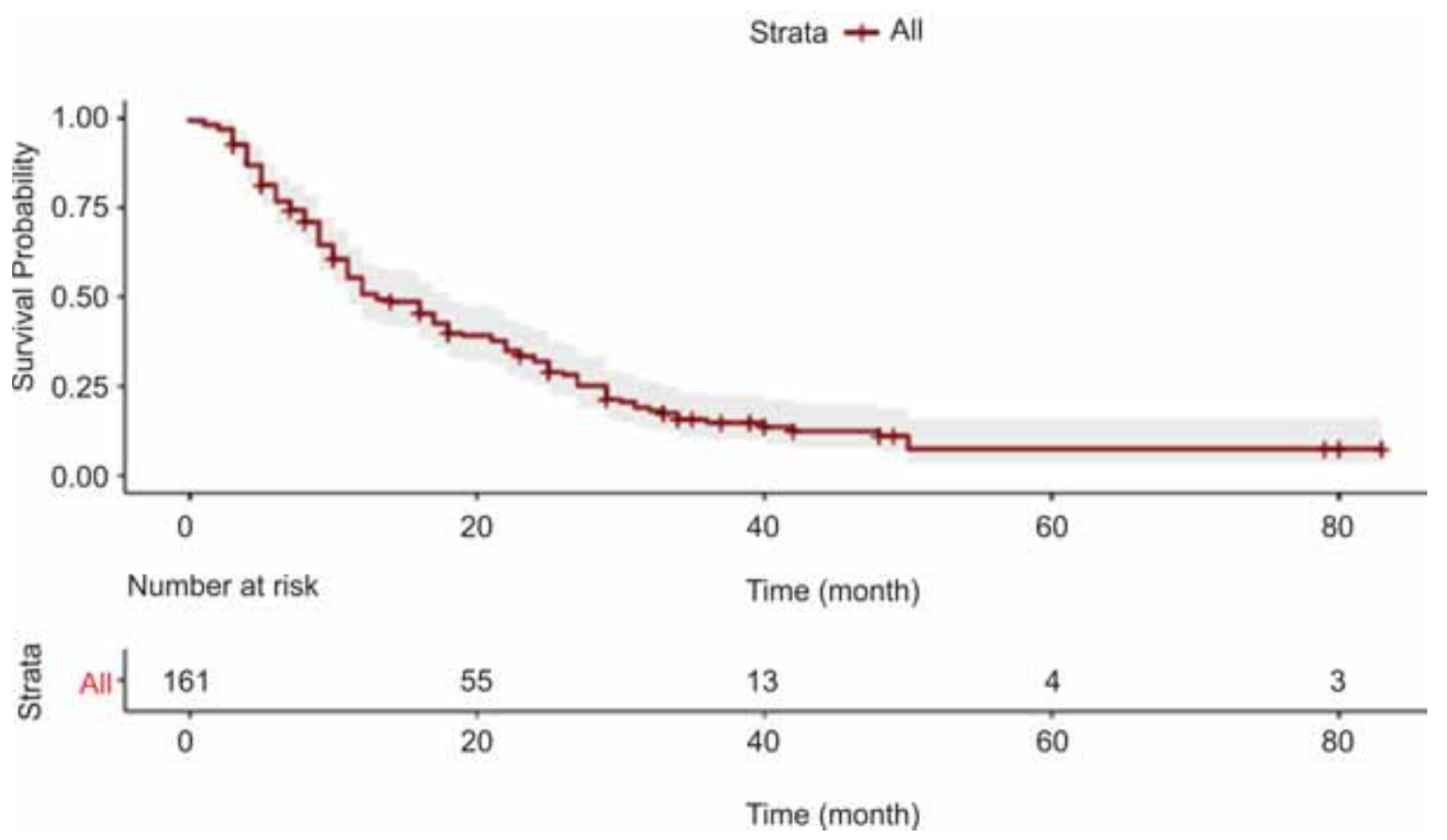

FIGURE 1. Survival curve OS Kaplan-Meier HCC General Survival

Mortality data:

\begin{tabular}{|l|l|l|l|}
\hline Strata & Restrictive Media $^{1}$ & Mediana & IC95\% Mediana \\
\hline Group & 21.60 & 13.00 & 11.00 at 18.00 \\
\hline
\end{tabular}

\begin{tabular}{|l|l|l|l|}
\hline Strata & Deceased & Survivals & Total \\
\hline Group & $131(81.36)$ & $30(18.64)$ & 161 \\
\hline
\end{tabular}

The mortality in our patients group was more than $80 \%$, with survival rate about 22 months and a median survival rate 13 months.

We perform an univariate analysis of OS and risk factors for every analyzed parameter used a long-rank test for compared Kaplan-Meier curves. 
Survival based on sex parameter was (Fig. 2):

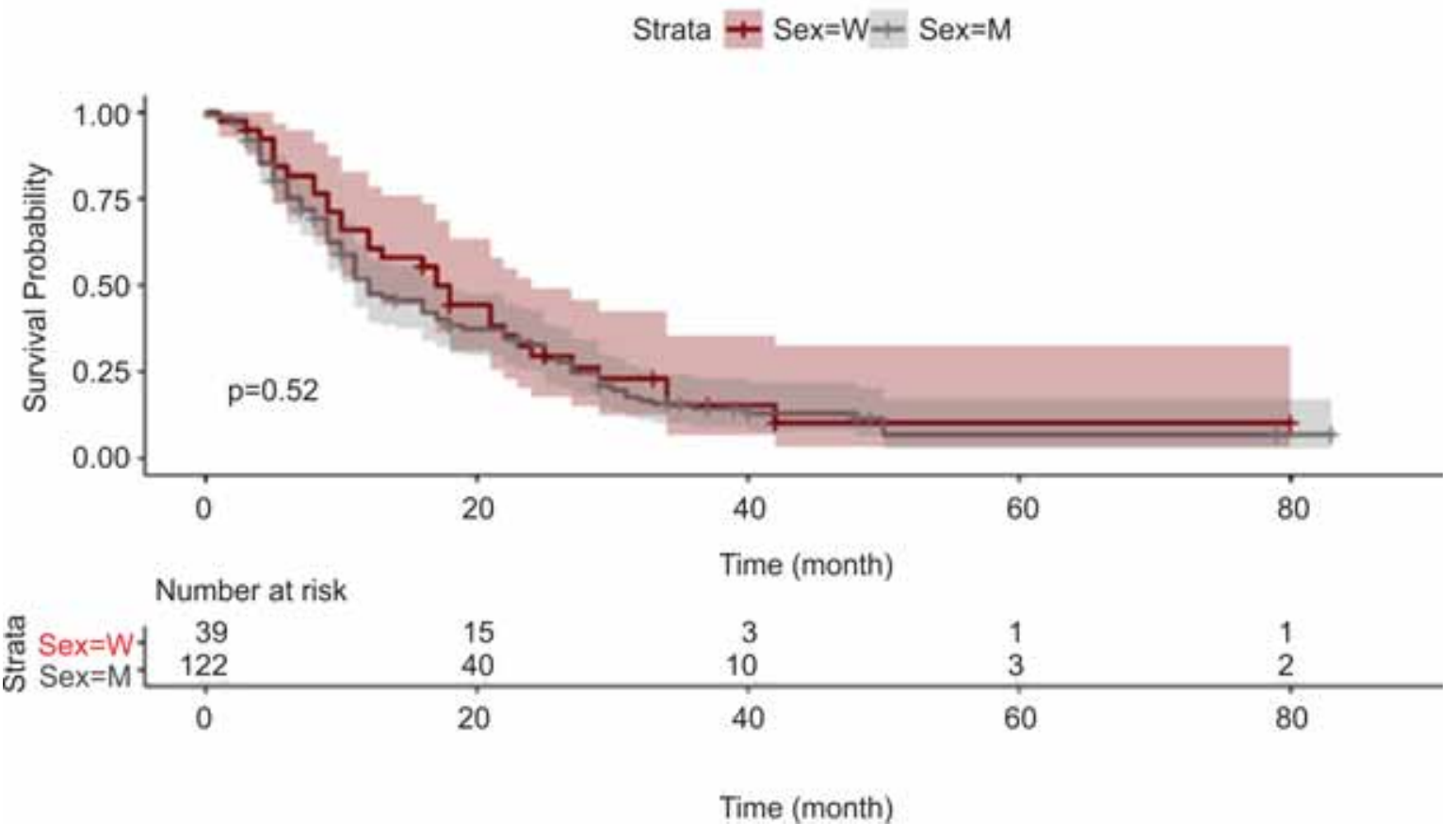

FIGURE 2. Survival curve OS Kaplan-Meier HCC based on sex parameter

\begin{tabular}{|l|l|l|l|}
\hline Strata Sex & Restrictivemedia & Median & IC95\% Median \\
\hline W & 23.70 & 17.00 & 12.00 at 24.00 \\
\hline M & 20.90 & 12.00 & 11.00 at 18.00 \\
\hline
\end{tabular}

We can observe a higher mortality for men ( $82 \%$ vs $79.50 \%$ ). To analyze mortality hazard, we used a Cox regression:

Even if survival seems to be better for women than men, long-rank test suggested that the differences are not statistically significant.

\begin{tabular}{|l|l|l|l|l|}
\hline Sex & Coefficient & Wald $\mathbf{z}$ & P value & HR [IC95\%] \\
\hline $\mathbf{W}$ & REFERENCE & - & - & - \\
\hline $\mathbf{M}$ & 0.136 & 0.662 & 0.508 & $\begin{array}{l}1.14[0.76 \text { at } \\
1.71]\end{array}$ \\
\hline
\end{tabular}

\begin{tabular}{|l|l|l|l|}
\hline Strata Sex & Deceased & Survivals & Total \\
\hline $\mathbf{W}$ & $31(79.48)$ & $8(20.52)$ & 39 \\
\hline $\mathbf{M}$ & $100(81.96)$ & $22(18.04)$ & 122 \\
\hline
\end{tabular}

The mortality hazard is 1.14 higher for men compared with women. 
We found survival rate based on HCC etiology (Fig. 3):

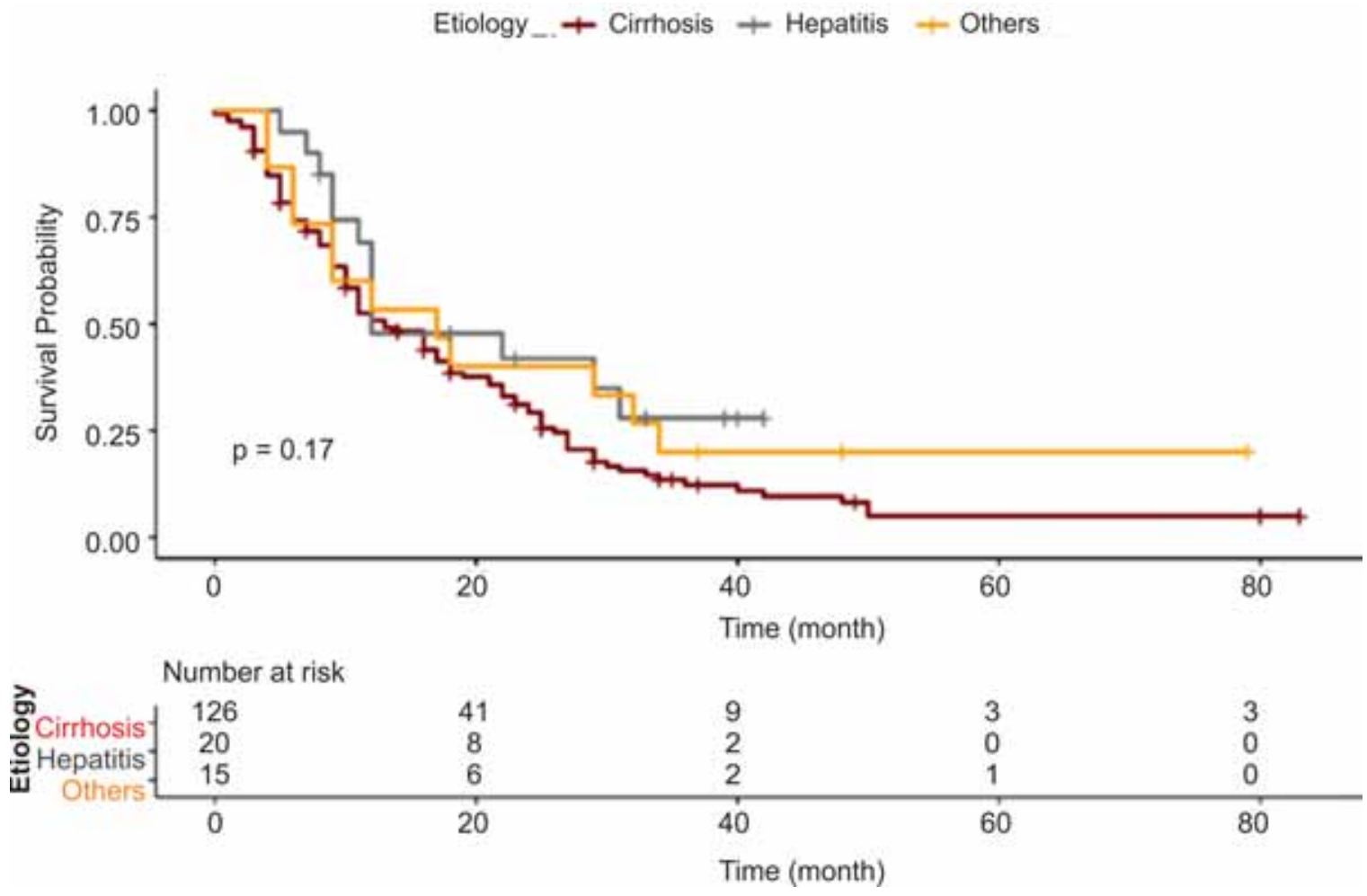

FIGURE 3. Survival curve OS Kaplan-Meier based on HCC etiology

\begin{tabular}{|l|l|l|l|}
\hline Strata Etiology & $\begin{array}{l}\text { Restrictive } \\
\text { media }\end{array}$ & Median & $\begin{array}{l}\text { IC95\% } \\
\text { Median }\end{array}$ \\
\hline Cirrhosis & 19.40 & 13.00 & 11.00 at 18.00 \\
\hline Hepatitis & 32.60 & 12.00 & 12.00 at N/A \\
\hline Others & 27.80 & 17.00 & 9.00 at N/A \\
\hline
\end{tabular}

The survival curves analysis demonstrated severe response for patients with cirrhosis $p$ value for log-rank test is small $(p=0.17)$.

\begin{tabular}{|l|l|l|l|}
\hline Strata Etiology & Deceased & Survivals & Total \\
\hline Cirrhosis & $106(84.12)$ & $20(15.88)$ & 126 \\
\hline Hepatitis & $13(65.00)$ & $7(35.00)$ & 20 \\
\hline Others & $12(80.00)$ & $3(20.00)$ & 15 \\
\hline
\end{tabular}

Cox regression demonstrate a better prognosis for patients with hepatitis compared with those with cirrhosis (a hazard mortality 0.63 lower than cirrhosis) (Fig. 4).

\section{Risk ratio}

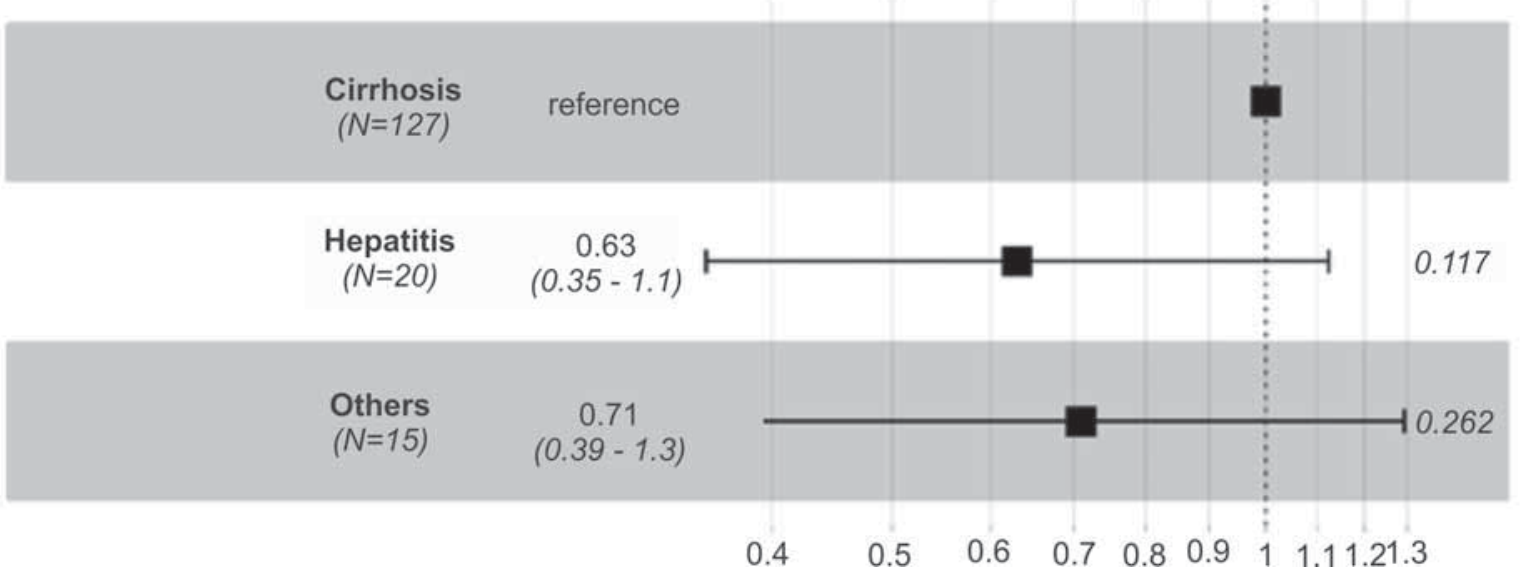

FIGURE 4. Risk mortality based on etiology 


\section{$\mathrm{VHB}+\mathrm{VHC}+\mathrm{VHB}+\mathrm{VHD}+$ Alcohol}

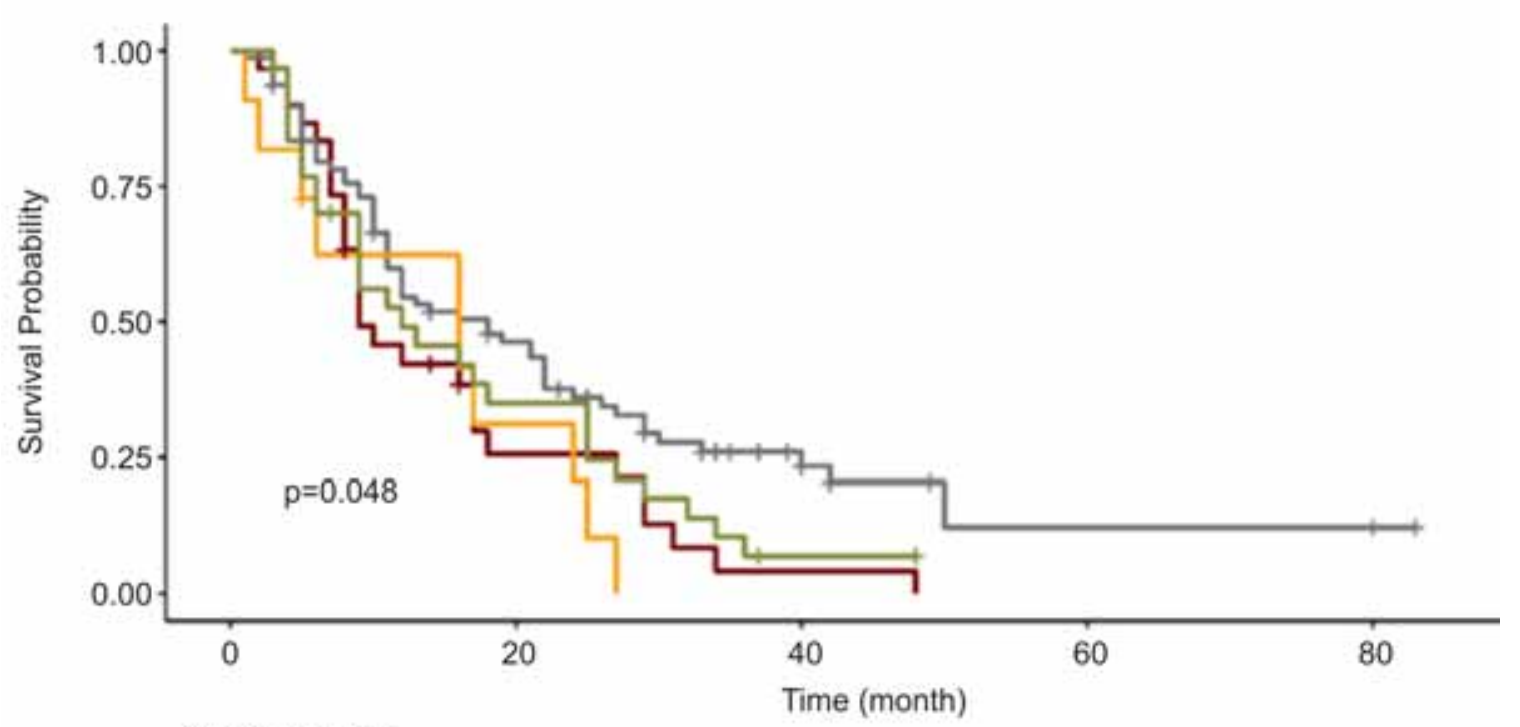

Number at risk

\begin{tabular}{rccccc} 
VHB & 30 & 6 & 1 & 0 & 0 \\
VHC & 79 & 32 & 10 & 3 & 3 \\
VHHB+VHD & 11 & 3 & 0 & 0 & 0 \\
Alcohol & 31 & 10 & 1 & 0 & 0 \\
\hline 0 & 20 & 40 & 60 & 80
\end{tabular}

FIGURE 5. Survival curve OS Kaplan-Meier HCC patients type of infection

Survival data:

\begin{tabular}{|l|l|l|l|}
\hline Strata & $\begin{array}{l}\text { Restrictive } \\
\text { media }\end{array}$ & Median & IC95\% Median \\
\hline VHB & 15.50 & 9.00 & 8.00 at 18.00 \\
\hline VHC & 22.10 & 18.00 & 11.00 at 24.00 \\
\hline VHB+VHD & 14.30 & 16.00 & 6.00 at N/A \\
\hline Alcohol & 17.20 & 12.00 & 9.00 at 25.00 \\
\hline
\end{tabular}

Our analysis shows the best survival rate for HCV infected patients, log-rank test reveals significant statistical differences between at least 2 strata $(p<0.05)$ (Fig 5).
Mortality data:

\begin{tabular}{|l|l|l|l|}
\hline Strata & Deceased & Survivals & Total \\
\hline VHB & $27(90.00)$ & $3(10.00)$ & 30 \\
\hline VHC & $58(73.41)$ & $21(26.59)$ & 79 \\
\hline VHB+VHD & $10(90.90)$ & $1(9.10)$ & 11 \\
\hline Alcohol & $27(87.09)$ & $4(12.91)$ & 31 \\
\hline
\end{tabular}

Cox regression demonstrated that HCV infection has a hazard mortality 2 times lower than HVB infection $(H R=0.58)$, with statistical significant rate $(p<0.05)$. VHD coinfection doesn't show a more sever prognosis $(H R=1.14$ but $p>$ 0.05).

\begin{tabular}{|l|l|l|l|l|}
\hline Etiology & Coefficient & Wald $\mathbf{z}$ & P value & HR [IC95\%] \\
\hline VHB & REFERENCE & - & - & - \\
\hline VHC & -0.538 & -2.282 & 0.022 & $0.58[0.36$ at 0.92$]$ \\
\hline VHB+VHD & 0.134 & 0.362 & 0.717 & $1.14[0.55$ at 2.37$]$ \\
\hline Toxic & -0.149 & -0.547 & 0.584 & $0.86[0.50$ at 1.47$]$ \\
\hline
\end{tabular}


Survival analysis based on Child-Pugh classification showed a better survival rate was for ChildPugh A patients $(p=0.07)$ compared with Child-Pugh B patients $(p=0.07)$ (Fig 6).

\section{Child-Pugh + A $+B$}

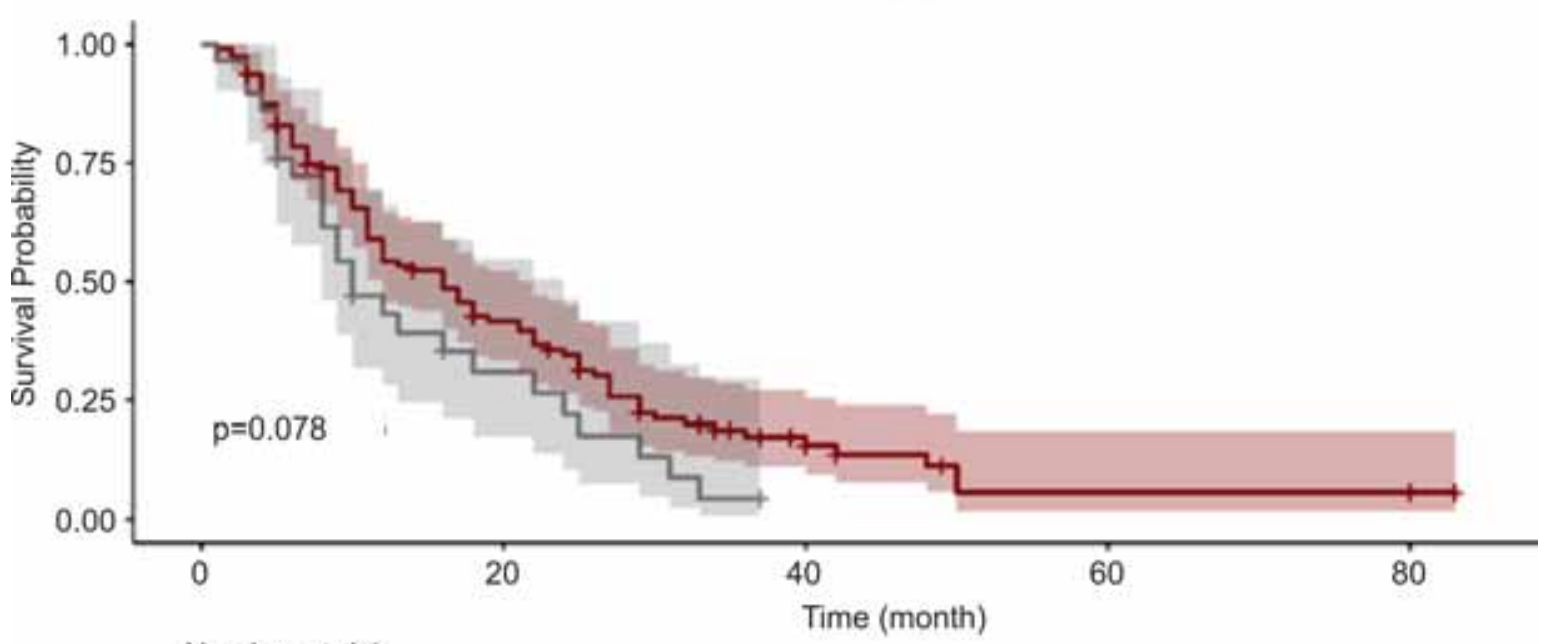

Number at risk

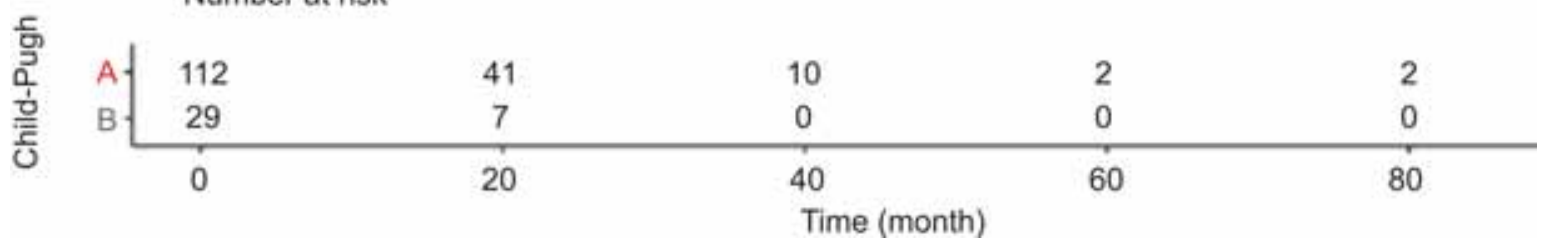

FIGURE 6. Survival curve OS Kaplan-Meier HCC patients Child-Pugh Classification

\begin{tabular}{|l|l|l|l|}
\hline Strata Child-Pugh & $\begin{array}{l}\text { Restrictive } \\
\text { media }\end{array}$ & Median & $\begin{array}{l}\text { IC95\% } \\
\text { Median }\end{array}$ \\
\hline A & 20.70 & 16.00 & 12.00 at 22.00 \\
\hline B & 15.60 & 10.00 & 8.00 at 24.00 \\
\hline
\end{tabular}

Child-Pugh B patients has a decease hazard 1.5 higher compared with Child-Pugh A patients.

\section{Cox regression:}

\begin{tabular}{|l|l|l|l|l|}
\hline Child-Pugh & Coefficient & Wald z & P value & HR [IC95\%] \\
\hline A & Reference & - & - & - \\
\hline B & 0.398 & 1.743 & 0.081 & $\begin{array}{l}1.48[0.95 \\
\text { at 2.33] }\end{array}$ \\
\hline
\end{tabular}

\begin{tabular}{|l|l|l|l|}
\hline Strata Child-Pugh & Deceased & Survivals & Total \\
\hline A & $90(80.35)$ & $22(19.65)$ & 112 \\
\hline B & $25(86.20)$ & $4(13.80)$ & 29 \\
\hline
\end{tabular}


Survival analysis based on presence of portal vein thrombosis was (Fig. 7):

\section{thrombosis + No + Yes}
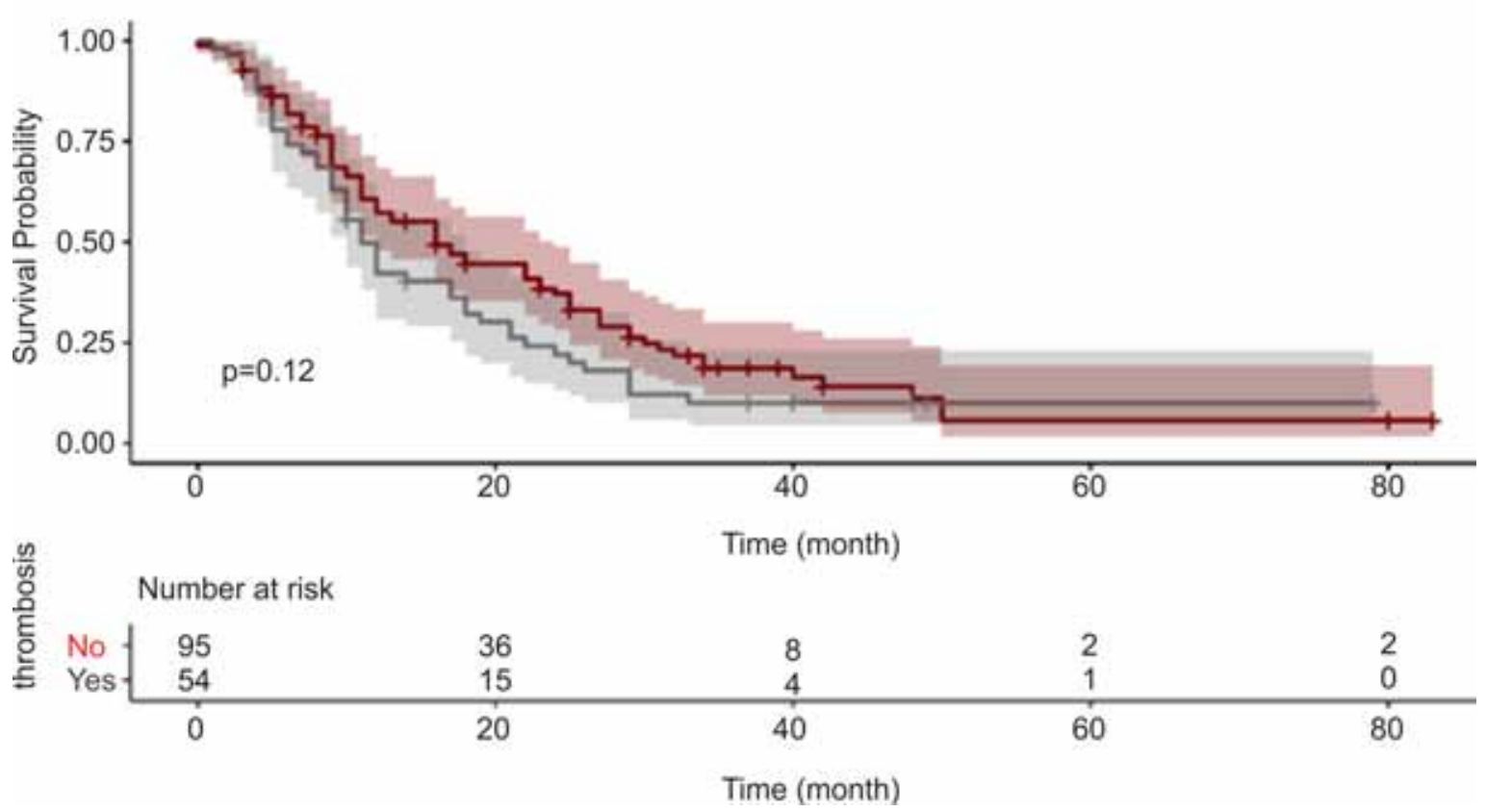

FIGURE 7. Survival curve OS Kaplan-Meier HCC patients with portal vein thrombosis

\begin{tabular}{|l|l|l|l|}
\hline $\begin{array}{l}\text { Strata Portal } \\
\text { vein thrombosis }\end{array}$ & $\begin{array}{l}\text { Restrictive } \\
\text { media }\end{array}$ & Median & IC95\% Median \\
\hline No & 22.80 & 16.00 & 12.00 at 24.00 \\
\hline Yes & 19.70 & 11.00 & 10.00 at 18.00 \\
\hline
\end{tabular}

The patients without portal vein thrombosis have a better survival rate compared with the patients with portal vein thrombosis.

\begin{tabular}{|l|l|l|l|}
\hline $\begin{array}{l}\text { Strata Portal } \\
\text { vein thrombosis }\end{array}$ & Deceased & Survivals & Total \\
\hline No & $74(77.89)$ & $21(22.11)$ & 95 \\
\hline Yes & $47(87.03)$ & $7(12.97)$ & 54 \\
\hline
\end{tabular}

Cox regression demonstrated that the hazard decease is 1.33 higher in portal vein thrombosis group compared with non-portal vein thrombosis patients ( $p=0.12$ ) (Fig. 8).

\begin{tabular}{|l|l|l|l|l|}
\hline $\begin{array}{l}\text { Portal vein } \\
\text { thrombosis }\end{array}$ & Coefficient & $\begin{array}{l}\text { Wald } \\
\mathbf{z}\end{array}$ & $\begin{array}{l}\mathbf{P} \\
\text { value }\end{array}$ & HR [IC95\%] \\
\hline Absence & REFERENCE & - & - & - \\
\hline Present & 0.287 & 1.538 & 0.124 & $\begin{array}{l}1.33[0.92 \text { at } \\
1.92]\end{array}$ \\
\hline
\end{tabular}

\section{Risk ratio}

thrombosis VP absence $(N=95)$

1.3 $(0.92-1.9)$ presence $(N=54)$

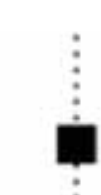

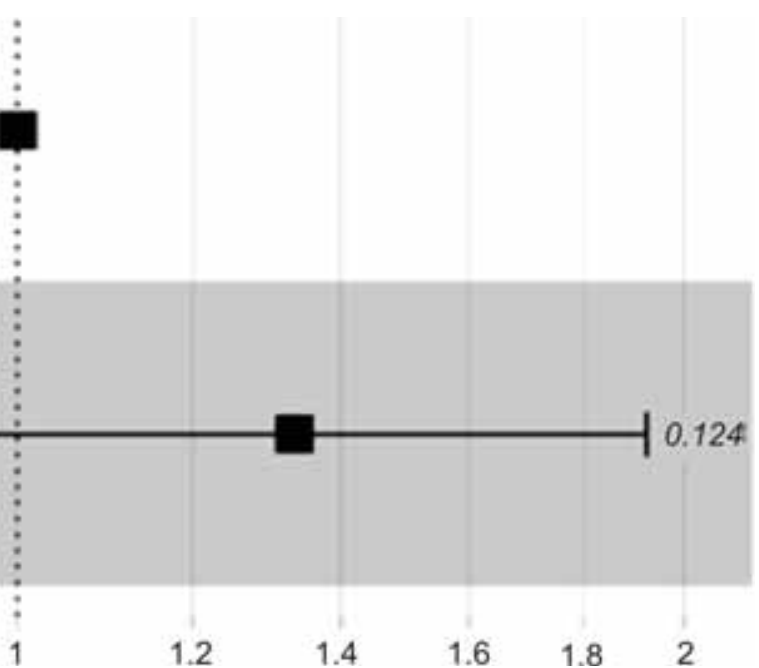

FIGURE 8. Risk mortality based on portal vein thrombosis 
Survival analysis based on lymph nodes presence showed (Fig. 9):

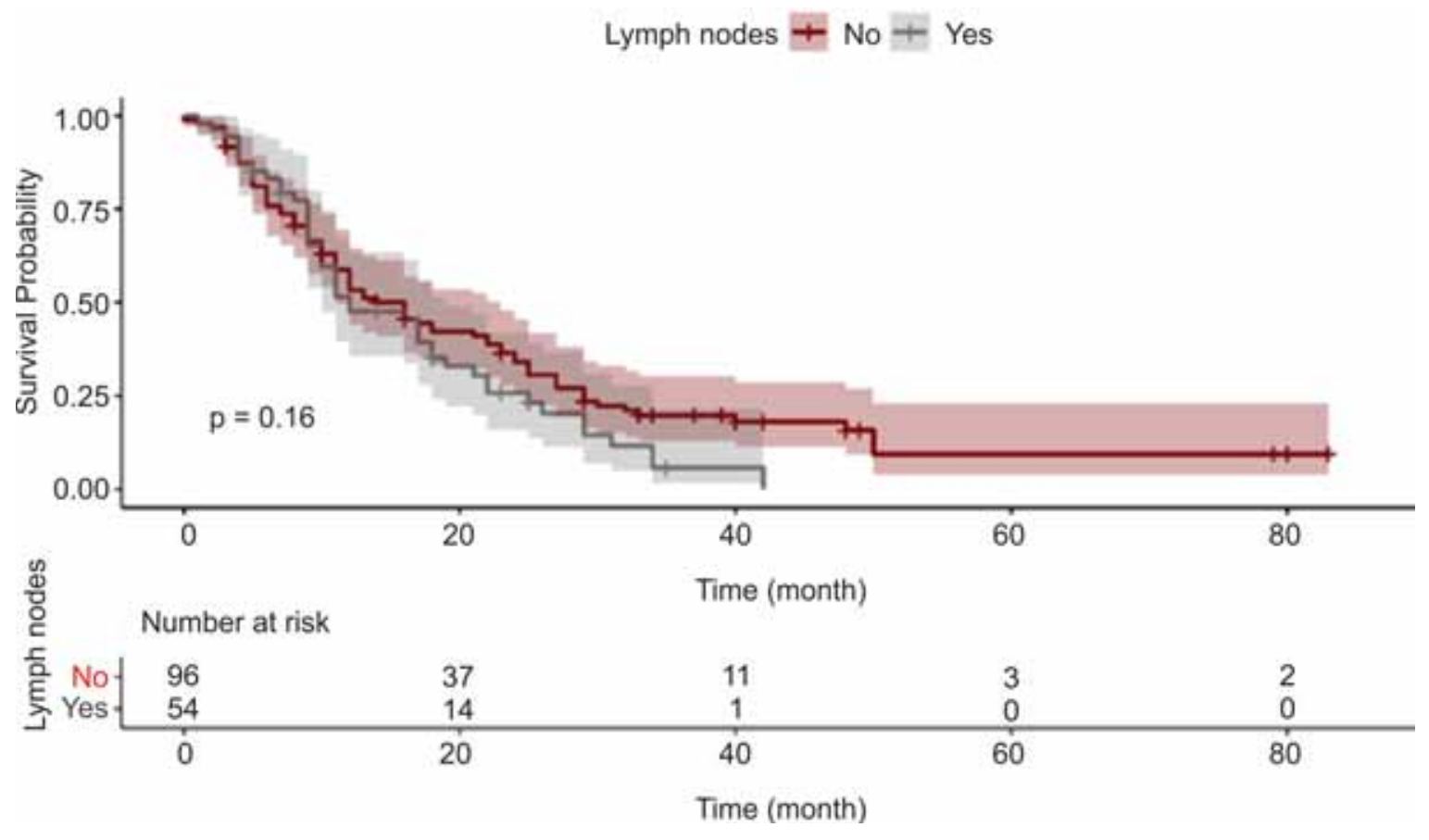

FIGURE 9. Survival curve OS Kaplan-Meier HCC patients with lymph nodes

The survival rate is better in the patients group without lymph nodes with a hazard decease 1.3 higher $(p=0.15)$.

\begin{tabular}{|l|l|l|l|}
\hline $\begin{array}{l}\text { Strata lymph } \\
\text { nodes }\end{array}$ & $\begin{array}{l}\text { Restrictive } \\
\text { media }\end{array}$ & Median & IC95\% Median \\
\hline No & 21.70 & 16.00 & 11.00 at 23.00 \\
\hline Yes & 16.60 & 12.00 & 10.00 at 19.00 \\
\hline
\end{tabular}

\begin{tabular}{|l|l|l|l|}
\hline $\begin{array}{l}\text { Strata lymph } \\
\text { nodes }\end{array}$ & Deceased & Survivals & Total \\
\hline No & $77(80.20)$ & $11(19.80)$ & 96 \\
\hline Yes & $45(83.33)$ & $9(16.67)$ & 54 \\
\hline
\end{tabular}

\section{Age analysis}

Because age is a permanent variable, we used a Cox regression for this analysis.

Cox regresssion:

\begin{tabular}{|l|l|l|l|l|}
\hline Variable & Coefficient & $\begin{array}{l}\text { Wald } \\
\mathbf{z}\end{array}$ & $\begin{array}{l}\mathbf{p} \\
\text { Value }\end{array}$ & HR [IC95\%] \\
\hline Age & 0.009 & 1.195 & 0.232 & $1.01[0.99$ at 1.02] \\
\hline
\end{tabular}

Our analysis does not consider age like a potential hazard factor for mortality $(p>0.05)$.

Treatment duration analysis is also a Cox regression:

\begin{tabular}{|l|l|l|l|l|}
\hline Variable & Coefficient & Wald z & P value & HR [IC95\%] \\
\hline $\begin{array}{l}\text { Treatment } \\
\text { duration }\end{array}$ & -0.087 & -7.624 & $<0.0001$ & $\begin{array}{l}0.91[0.89 \\
\text { at } 0.93]\end{array}$ \\
\hline
\end{tabular}

A longer period of treatment is associated with a low hazard decease, one month more therapy decrease the hazard decease 0.91 times, this effect is consider statistical significant $(p<0.01)$.

\section{DISCUSSION}

Sorafenib is the first FDA-approved systemic therapy for patients with advanced HCC not amenable to treatment by surgical resection or liver transplantation. In clinical practice, sorafenib generally is not given until such patients have failed to respond to locoregional therapies such as transcatheter arterial chemoembolization (TACE). A number of prospective clinical trials have assessed the anti-HCC effects of sorafenib alone, sorafenib with systemic chemotherapy, and sorafenib with locoregional therapy.

In literature, there are 7 sorafenib-alone trials, which included a total of 1,072 patients. Two reports described phase 3 randomized, placebo-controlled clinical trials $(16,17)$, three de- 
scribed phase 2 trials (18-20) and two described phase 1 trials $(21,22)$. The percentage of male patients ranged from $71 \%(18)$ to $100 \%$ (22). Median age ranged from 51 (17) to 72 years (19). Among the five trials providing precise OS data $(16-18,20,21)$, OS ranged from 5 (20) to 15.6 months (21) in the patients who received sorafenib.

The SHARP and Asian-Pacific $(16,17)$ studies were the two highest quality reports (phase 3 randomized, placebo-controlled trials). The large majority of patients in both studies had Child A cirrhosis (95\% and 97\%), but the frequency of hepatitis B infection was considerably higher in the Asian-Pacific trial ( $71 \%$ vs. $19 \%$ ). For the sorafenib and placebo groups in the SHARP trial, the OS was 10.7 vs. 7.9 months $(P<$ $0.05)$ (16). For the sorafenib and placebo groups in the Asian-Pacific trial, the OS was 6.5 vs. 4.2 months.

We perfom a study with sorafenib alone to see the efficacy of sorafenib in treating advanced HCC using overall survival. Also we find out the efficacy of sorafenib treatment depending on gender, age, stage of cirrhosis, and etiology of the underlying liver disease (especially hepatitis $B$ and hepatitis $C$ ).

Sorafenib provides statistically significant, but clinically modest, improvements in OS (8). The large majority of patients included in the reports were men who had HCC associated with Child-Pugh A cirrhosis (9). Our systematic re- view does suggest that patients with hepatitis $B$ infection might have a poorer response to sorafenib treatment than patients with hepatitis $C$. The trial with the highest percentage of hepatitis B patients (90\%) described the lowest OS (5 months) and DFS (26\%) (10), whereas the trial with the highest percentage of hepatitis $C$ patients (74\%) had the longest OS (15.6 months) and the highest DFS (82\%) (11). Further studies that directly compare the response to sorafenib in patients who have HCC associated with hepatitis $B$ and $C$ are needed to establish this relationship.

This study confirms the benefit of sorafenib in OS, namely in Child-Pugh A patients. According to the Child-Pugh class, Child-Pugh A patients had a significantly higher median survival versus Child-Pugh B. Therefore, liver function of patients in sorafenib therapy is an important prognostic factor of survival.

\section{CONCLUSIONS}

Sorafenib, in daily practice, has proven to be more effective than in registration trials regarding overall survival (SHARP 10.7 months). Also, the median overall survival recorded in this study was slightly longer than in GIDEON study (12.1 months for the $800 \mathrm{mg} /$ day group), probably administrating Sorafenib beyond progression, until patients had clinical benefit.

\section{REFERENCES}

1. Parkin DM, Bray F, Ferlay J et al. Global cancer statistics, 2002. CA Cancer J Clin. 2005:55:74-108.

2. Pons-Renedo F, Llovet JM. Hepatocellular carcinoma: a clinical update. MedGenMed. 2003:5:11.

3. Cancer Facts \& Figures 2010. American Cancer Society; Atlanta, Geogia: 2010.

4. El-Serag HB. Epidemiology of hepatocellular carcinoma in USA. Hepatol Res. 2007;37 (Suppl 2):S88-94.

5. El-Serag HB, Davila JA, Petersen NJ et al. The continuing increase in the incidence of hepatocellular carcinoma in the United States: An update. Ann Intern Med. 2003;139:817-23. [PubMed].

6. El-Serag HB, Mason AC. Rising incidence of hepatocellular carcinoma in the United States. N Engl J Med. 1999;340:745-50. [PubMed].

7. NHANES III data. 2008.
8. Llovet JM, Ricci S, Mazzaferro V et al. Sorafenib in advanced hepatocellular carcinoma. N Engl J Med. 2008;359(4):378390.

9. Massa ESC et al. Efficacy, safety and impact on quality of life of a treatment with sorafenib in elderly cancer patients with advanced hepatocellular carcinoma. Result of a phase II study. Annals of Oncology. 2009;20(Suppl 8):s65.

10. Yau T, Chan P, Ng KK et al. Phase 2 open-label study of single-agent sorafenib in treating advanced hepatocellular carcinoma in a hepatitis B-endemic Asian population: presence of lung metastasis predicts poor response. Cancer. 2009;115:428-36.

11. Furuse J, Ishii H, Nakachi K et al. Phase I study of sorafenib in Japanese patients with hepatocellular carcinoma. Cancer Sci. 2008;99:159-65.
12. Castroagudin JFME et al. Short-term efficacy and safety of treatment of advanced hepatocellular carcinoma with sorafenib. Journal of Hepatology. 2008;48(362 Suppl 2):s141-s142.

13. Wilhelm SM, Carter C, Tang L et al. BAY 43-9006 exhibits broad spectrum oral antitumor activity and targets the RAF/ MEK/ERK pathway and receptor tyrosine kinases involved in tumor progression and angiogenesis. Cancer Res. 2004;64:7099109.

14. Wilhelm SM, Adnane L, Newell P et al. Preclinical overview of sorafenib, a multikinase inhibitor that targets both Raf and VEGF and PDGF receptor tyrosine kinase signaling. Mol Cancer Ther. 2008;7:3129-40.

15. Llovet J et al. Sorafenib improves survival in advanced hepatocellular carcinoma (HCC): Results of a Phase III randomized 
placebo-controlled trial (SHARP trial); Proceedings from the American Society of Clinical Oncology Conference; Chicago, IL: 2007.

16. Llovet JM, Ricci S, Mazzaferro V et al. Sorafenib in advanced hepatocellular carcinoma. N Engl J Med. 2008;359:37890.

17. Cheng AL, Kang YK, Chen Z et al. Efficacy and safety of sorafenib in patients in the Asia-Pacific region with advanced hepatocellular carcinoma: A phase III randomised, double-blind, placebo- controlled trial. Lancet Oncol. 2009; 10: 25-34.

18. Abou-Alfa GK, Schwartz L, Ricci S et al. Phase II study of sorafenib in patients with advanced hepatocellular carcinoma. J Clin Oncol. 2006; 24: 4293-300.

19. Massa ESC et al. Efficacy, safety and impact on quality of life of a treatment with sorafenib in elderly cancer patients with advanced hepatocellular carcinoma. Result of a phase II study. Annals of Oncology. 2009; 20 (Suppl 8):s65.

20. Yau T, Chan P, Ng KK et al. Phase 2 open-label study of single-agent sorafenib in treating advanced hepatocellular carcinoma in a hepatitis B-endemic Asian population: Presence of lung metastasis predicts poor response. Cancer. 2009; 115: 428-36.

21. Furuse J, Ishii $\mathrm{H}$, Nakachi $\mathrm{K}$ et al. Phase I study of sorafenib in Japanese patients with hepatocellular carcinoma. Cancer Sci. 2008; 99: 159-65

22. Castroagudin JFME et al. Shor-term efficacy and safety of treatment of advanced hepatocellular carcinoma with sorafenib. Journal of Hepatology. 2008; 48(362 Suppl 2):s141-s142. 